\section{DOCUMENT LISTS LATEX-FREE LOCAL ANAESTHETICS}

In June 2011, the $B D J$ reported on a new online resource published by the UK Medicines Information Service listing toothpastes widely available in the UK and the excipients they contain. ${ }^{1}$ The Service has now produced another document for dentists called Which dental local anaesthetics are latex-free?

According to the document, between 1-6\% of the general population are potentially sensitised to natural rubber latex (NRL). Contact between NRL and a mucosal surface causes a more severe reaction than contact with intact skin and people sensitised to NRL should therefore avoid contact with all products containing it.
The document is available for free online at: www.nelm.nhs.uk/en/NeLM-Area/Evidence/MedicinesQ--A/Which-dental-local-anaesthetics-are-latexfree/?query=latex\&trank=100

1. News article. New resource will aid patient toothpaste choice. Br Dent J 2011; 210: 562

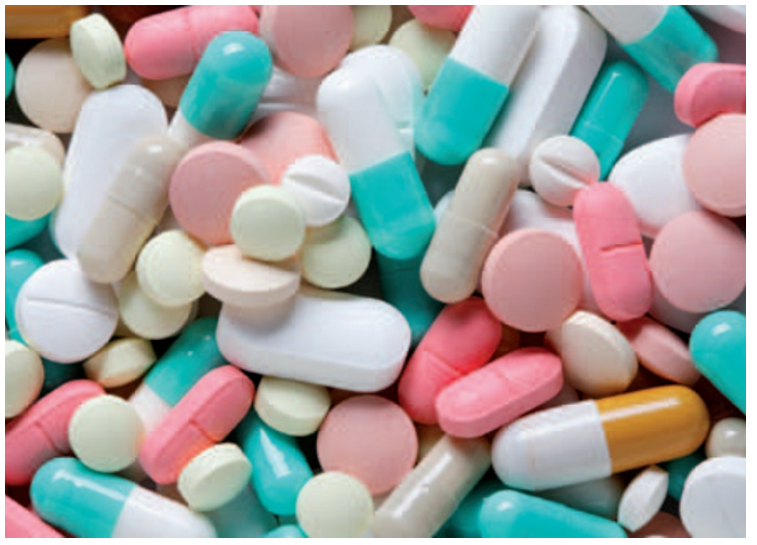

\section{PROPOSALS RECOMMEND LEADING ROLE FOR DENTAL PROFESSIONALS IN HALTING USE OF SMOKELESS TOBACCO}

Dentists, dental nurses and dental hygienists may be asked to play a leading role as part of new proposals to stop the use of smokeless tobacco by people of South Asian origin in the UK. The National Institute for Health and Clinical Excellence (NICE) have published a consultation on their proposals which recommends a key intervention and education role for dental professionals.

NICE is also recommending more training for dental professionals to help them gain a greater understanding of smokeless tobacco including terminology, symptoms and approaches to successful intervention. Smokeless tobacco is associated with a number of health problems including nicotine addiction, mouth and oral cancer, periodontal disease, heart attacks and strokes, problems in pregnancy and following childbirth and late diagnosis of dental

problems as smokeless tobacco products can often mask pain.

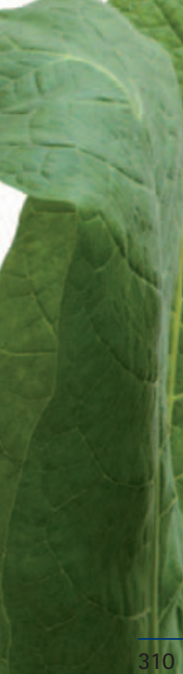

